\title{
ESTUDIO EXPERIMENTAL DE ALTERACIÓN TÉRMICA SOBRE EXOESQUELETOS DE MOLUSCOS MARINOS (NACELLA MAGELLANICA) Y SUS IMPLICANCIAS PARA LA INTERPRETACIÓN DE CONJUNTOS ARQUEOMALACOLÓGICOS DE CONCHEROS EN PATAGONIA ARGENTINA ${ }^{5}$
}

\author{
Experimental study of thermal alteration on exoskeletons of marine \\ molluscs (Nacella magellanica) and its implications for the \\ interpretation of arqueomalacological assemblages of shell middens \\ in Patagonia argentina
}

Heidi Hammond ${ }^{6}$ y María Laura Ciampagna;Error! Marcador no definido. ${ }^{7}$

\section{Resumen}

Se presentan los resultados del programa experimental realizado sobre exoesqueletos calcáreos actuales de Nacella magellanica (Patellidae, Gasteropoda). Esta especie de molusco es una de las principales que compone los concheros arqueológicos en Patagonia continental argentina. Se buscó obtener evidencias de rasgos diagnósticos y modificaciones generadas sobre los exoesqueletos como consecuencia del proceso de exposición térmica. Diferentes muestras fueron sometidas a la quema controlada bajo condiciones de laboratorio en una mufla con termocupla digital para obtener mayor control sobre las temperaturas $\left(\right.$ de $0^{\circ} \mathrm{C}$ a $700^{\circ} \mathrm{C}$ ). Se llevó a cabo el análisis estructural, cromático y textural de las muestras expuestas al calor. Se realizó una primera aproximación a la aplicación de los indicadores obtenidos en el trabajo experimental para el estudio y la interpretación de conjuntos arqueomalacológicos recuperados en excavaciones sistemáticas en concheros de la costa norte de Santa Cruz, Patagonia argentina. Esta información se complementó con estudios antracológicos de carbones recuperados en los mismos sitios. La contrastación de los resultados experimentales y de los restos arqueomalacológicos permitió estimar que las conchas arqueológicas habrían estado sometidas hasta temperaturas de entre $300^{\circ} \mathrm{C}$ y $400^{\circ} \mathrm{C}$. Finalmente, se destaca la importancia del enfoque experimental para comprender características de materiales que conforman los sitios arqueológicos.

\footnotetext{
${ }^{5}$ Recibido el 04/04/2018. Aceptado el 08/01/2019. http://doi.org/10.15366/baexuam2018-19.13.002

${ }^{6}$ Consejo Nacional de Investigaciones Científicas y Técnicas (CONICET). División Arqueología, Facultad de Ciencias Naturales y Museo, Universidad Nacional de La Plata. Paseo del Bosque S/N, La Plata, Argentina. ORCID: 0000-0003-0351-5993. E-mail: heidihammondunlp@gmail.com

${ }^{7}$ Consejo Nacional de Investigaciones Científicas y Técnicas (CONICET). División Arqueología, Facultad de Ciencias Naturales y Museo, Universidad Nacional de La Plata. Paseo del Bosque S/N, La Plata, Argentina. ORCID: 0000-0003-3305-7145. E-mail: mlciampagna@gmail.com
} 
Palabras clave: Arqueología experimental; acción térmica; Nacella magellanica; arqueomalacología; Patagonia continental argentina.

\begin{abstract}
The results of the experimental program on current calcareous exoskeletons of Nacella magellanica (Patellidae, Gasteropoda) are presented. This species of mollusc is one of the main that composes the archaeological shell middens in continental Patagonia argentine. We sought to obtain evidence of diagnostic features and modifications generated on the exoskeletons as a consequence of the thermal exposure process. Different samples were submitted to controlled burning under laboratory conditions in a muffle with digital thermocouple to obtain greater control over temperatures (from $0^{\circ} \mathrm{C}$ to $700^{\circ} \mathrm{C}$ ). Structural, chromatic and textural analysis of samples exposed to heat were carried out. A first approach to the application of the indicators obtained in the experimental program for the analysis and interpretation of arqueomalacológicas assemblages recovered in systematic excavations in shell middens on the northern coast of Santa Cruz, Patagonia Argentina, was performed. This information was complemented with anthracological studies of carbons recovered in the same sites. The analysis of the experimental results and archaeomalacological remains allowed us to estimate that archaeological shells would have been subjected to temperatures of between $300^{\circ} \mathrm{C}$ and $400^{\circ} \mathrm{C}$. Finally, the importance of the experimental approach is highlighted to understand characteristics of materials that make up the archaeological sites.
\end{abstract}

Key words: Experimental archaeology; thermal action; Nacella magellanica; archaeomalacology; continental Patagonia argentine.

\title{
1. INTRODUCCIÓN
}

En el territorio argentino los sitios arqueológicos concheros se distribuyen a lo largo de las costas de Patagonia continental y Tierra del Fuego (Arrigoni y Paleo, 1992; Castro et al., 2003; Gómez Otero, 2006; Favier Dubois y Borella, 2007; Muñoz et al., 2009; Orquera y Piana, 1999a, 2000, 2001; Álvarez et al., 2011; Zubimendi et al., 2005, 2015; Hammond et al., 2013; Santiago et al., 2015; Zangrando et al., 2014; Hammond, 2015; entre otros). En Patagonia continental los concheros están conformados, entre otros materiales, por diversas especies de moluscos con valor alimenticio entre las que predominan los Venéridos hacia el norte, y especies de mitílidos -Mytilus edulis y Aulacomya atra- y gasterópodos -Nacella magellanica- hacia el sur en asociación a la provincia biogeográfica Magallánica y mesolitorales duros (Zubimendi et al., 2015). En Tierra del Fuego los conchales están formados principalmente por mitílidos de la especie Mytilus edulis (Orquera y Piana, 1992, 2000, 2001).

En el área de estudio de la costa norte de la provincia de Santa Cruz (CNSC; Figura 1) las tres especies principales de moluscos seleccionadas como alimento por los grupos cazadores recolectores fueron el gasterópodo Nacella magellanica (Lapa), y los bivalvos Aulacomya atra (Cholga) y Mytilus edulis (Mejillón) (Zubimendi, 2012; Hammond, 2013, 2015; 
Hammond y Zilio, 2016a). En los concheros los moluscos fueron explotados y procesados fundamentalmente con fines alimenticios. Generalmente en este tipo de sitios costeros es posible identificar evidencias de áreas de combustión (Pique i Huerta, 1999; Ortega y Marconetto, 2009; Ciampagna, 2015), las cuales pueden relacionarse con la cocción de los mariscos y otros recursos para la subsistencia, con el uso del fuego para la apertura de las especies de bivalvos y con la realización de diferentes actividades sociales cotidianas cercanas a estas áreas, las cuales son una fuente potencial de luz y calor (Pique i Huerta, 1999:49).

En los concheros de la CNSC no se han diferenciado estructuras discretas de combustión o fogones (Ciampagna, 2015), sino que los restos antracológicos producto de la quema de maderas generalmente se presentan como mantos continuos y planos (concentración de carbones) o áreas de combustión (sensu Pique i Huerta, 1999:126). Se identificaron evidencias de procesos de combustión en los sitios a partir de la presencia de materiales arqueológicos termoalterados, como restos óseos faunísticos, artefactos líticos y residuos como fragmentos de carbón disperso y cenizas (Hammond, 2015:542-543).

Diversos estudios experimentales acerca de los efectos de la exposición térmica sobre exoesqueletos de moluscos han sido desarrollados con el fin de interpretar las temperaturas a las que fueron expuestos los materiales en las áreas de combustión de los sitios y los efectos de la acción térmica en los restos (Bonizzoni et al., 2009; Villamarzo, 2009; Villagrán et al., 2011). Estas investigaciones tienen implicancias en los análisis tafonómicos y de fragmentación de los materiales (Claassen, 1998; Gutiérrez Zugasti, 2008a; Villagrán, 2011), en la evaluación de posibles prácticas de cocción o tratamiento de los alimentos para el consumo (Stiner et al., 2003) y en el análisis de las formas de uso del espacio en el pasado.

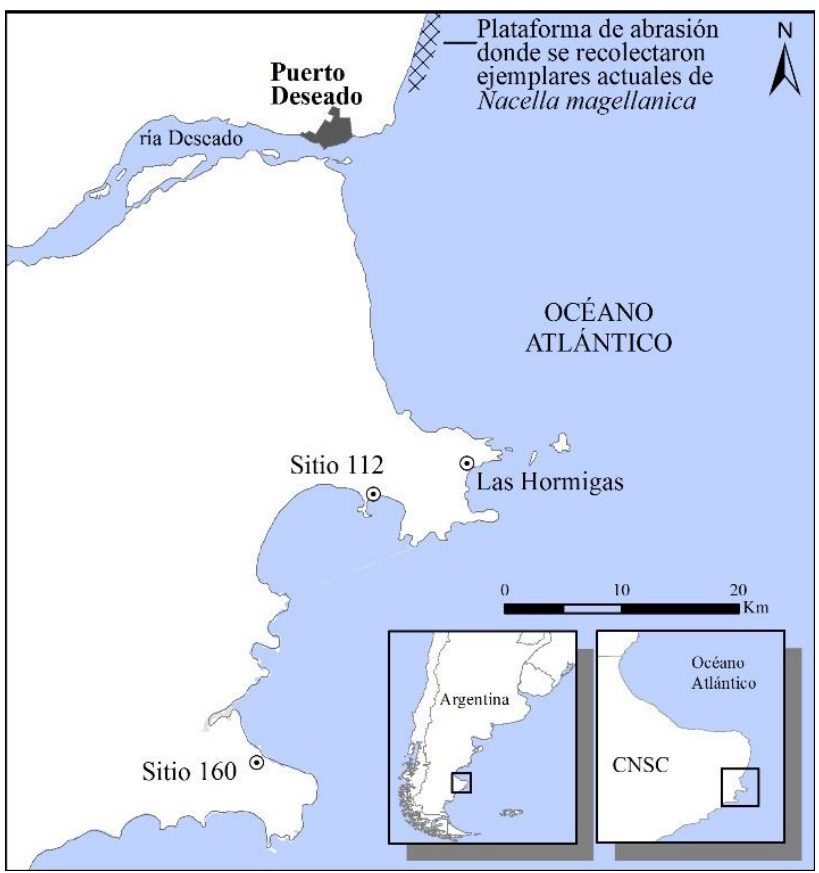

Figura 1. Área de estudio, ubicación de los concheros analizados y de la plataforma de abrasión donde se recolectaron los moluscos de la especie Nacella magellanica

El objetivo de este trabajo es analizar las modificaciones generadas sobre el exoesqueleto calcáreo del molusco de la especie Nacella magellanica (Patellidae, Gasteropoda) e 
identificar rasgos diagnósticos como producto del proceso de alteración térmica. Se pretende desarrollar un esquema de las alteraciones que sufren los exoesqueletos expuestos al calor que pueda servir para realizar comparaciones y formular hipótesis sobre los efectos de la exposición térmica de los moluscos recuperados en sitios arqueológicos. Para ello se desarrolló un programa experimental con conchas actuales de Nacella magellanica. Se espera que los resultados obtenidos aporten datos para la realización de estudios tafonómicos de restos malacológicos recuperados en contextos arqueológicos tanto de Patagonia como de otras partes del mundo donde también se han identificado ejemplares de moluscos de la familia Patellidae en sitios costeros (Jerardino, 1997; Cabral et al., 2003; Gutiérrez Zugasti, 2008a; entre otros).

Finalmente, se presenta una aproximación a las implicancias de los resultados del trabajo experimental en el análisis e interpretación de muestras arqueológicas obtenidas a partir de excavaciones sistemáticas en concheros del área CNSC (Fig. 1). En este sentido, se incluyen en la discusión los resultados de los estudios antracológicos de carbones recuperados en los concheros (Ciampagna, 2015, 2016).

\section{LA ESPECIE MALACOLÓGICA NACELLA MAGELLANICA}

Los moluscos de la especie Nacella magellanica presentan un exoesqueleto calcáreo o concha univalva del tipo patelliforme; sólida, cónica, generalmente algo aplastada en el ápice, sin enroscamiento, simétrica y con abertura grande ovalada a circular. La superficie externa consta de costillas radiales y/o escultura concéntrica y el interior de la concha es nacarado (Figura 2; Otaegui, 1974; Aguirre y Farinati, 2000:255). El exoesqueleto presenta microestructura foliada calcítica, y de acuerdo a estudios de conchas de lapas (Patellogastropoda, subclase que incluye los organismos del género Nacella) estas poseen cinco capas laminadas. Estas capas se dividen en exteriores e interiores por un miostraco que corresponde a la inserción de los músculos en la concha. Cada una de estas capas se inclina a pequeños ángulos de acuerdo a la morfología del exoesqueleto y su distribución es visible como en anillos concéntricos en vista ventral (Cohen y Branch, 1992; Fuchigami y Sasaki, 2005; Suzuki et al., 2010). La capa más externa se compone de sub-granos, con una pequeña variación de orientación de los cristales (Fuchigami y Sasaki, 2005). 
Estos organismos se movilizan de manera lenta y pasiva, y se distribuyen preferentemente en plataformas de abrasión rocosas en el intermareal medio y superior. La concha funciona principalmente en la protección mecánica y/o termodinámica de las partes blandas del animal.
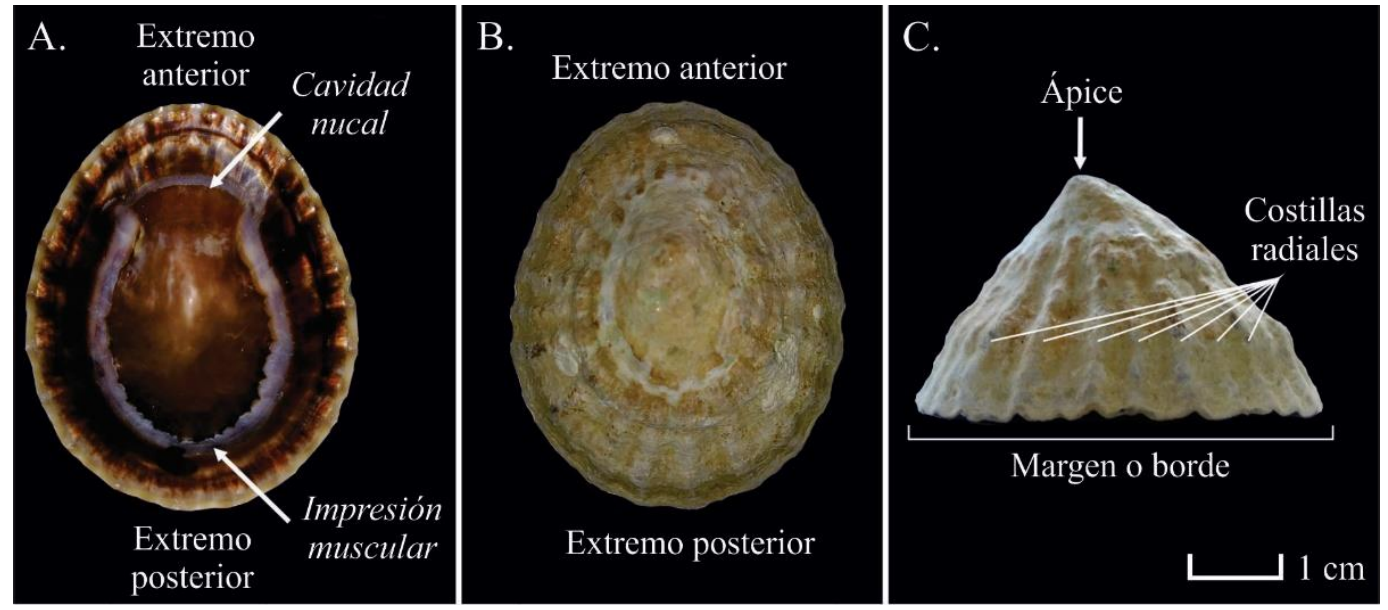

Figura 2. A. Cara interna y orientación de la concha de Nacella magellanica. B. Cara externa. C. Vista lateral externa.

\section{ANTECEDENTES SOBRE LA RECOLECCIÓN Y PROCESAMIENTO DE GASTERÓPODOS PATELLIFORMES}

\subsection{Recolección}

Son escasos los antecedentes acerca de la recolección de moluscos patelliformes por las poblaciones en el pasado. Para la recolección manual de individuos de especies móviles, como Nacella magellanica, se habrían empleado instrumentos para desprender los moluscos del sustrato duro al que viven adheridos. Los instrumentos podrían haber estado representados por artefactos líticos (Pailler et al., 2007; Gutiérrez Zugasti, 2008b), por palos biselados u horquillas espatuladas, tal como fue observado entre los grupos Selk'nam de Tierra del Fuego, o por algún otro tipo de artefacto de materia prima resistente, como por ejemplo hueso (Gusinde, 1986 [1937]; Orquera y Piana, 1999b).

Diversos autores han sugerido que la presencia de roturas o signos de impacto en conchas patelliformes recuperadas en contextos arqueológicos podrían corresponder a evidencias generadas como consecuencia del proceso de recolección de los moluscos (Angelbeck, 2011; Orton y Halkett, 2006; Orton et al., 2012; Verdún, 2014; Hammond, 2013, 2015; Hammond y Zilio, 2016b). Recientemente se llevó a cabo un estudio experimental de recolección de moluscos de la especie Nacella magellanica en la CNSC. Se interpretó que las roturas y evidencias de impacto en los conjuntos arqueomalacológicos de concheros efectivamente podrían ser consecuencia de la aplicación de golpes producidos con el empleo de instrumentos de materia prima dura por los grupos humanos durante el proceso de recolección de esta especie de gasterópodo para generar su desprendimiento de las plataformas de abrasión rocosas (Hammond y Zilio, 2016b). 


\subsection{Procesamiento}

Diversas especies de mitílidos, como por ejemplo Mytilus edulis o Aulacomya atra, deben ser sometidas al calor para producir la apertura de las valvas, las cuales se cierran fuertemente al ser recolectadas. En el caso de las lapas y los caracoles, el calentamiento no es necesario o requiere un tiempo menor que los mitílidos. Las informaciones etnográficas del siglo XIX señalan que los grupos Yaganes de Tierra del Fuego cocinaban los mejillones al calor del fuego o al rescoldo, en tanto las lapas podían ser sometidas a ese mismo procedimiento o ser comidas crudas (Orquera, 1999).

\section{ANTECEDENTES SOBRE LOS EFECTOS DE LA ALTERACIÓN TÉRMICA EN EXOESQUELETOS CALCÁREOS DE MOLUSCOS}

La mineralogía de la concha, la temperatura y la duración de la exposición al calor son variables que influyen en las transformaciones que pueda sufrir el exoesqueleto calcáreo (Gaffey et al., 1991). En los exoesqueletos expuestos al calor se genera la alteración de la estructura cristalográfica y la textura. Los restos termoalterados se fracturan más fácilmente y se produce la pérdida de peso debido al daño de la estructura y la pérdida de humedad (Gaffey et al., 1991; Claassen, 1998; Maritan et al., 2007; Faulkner, 2011). Se ha postulado que los cambios microestructurales de las conchas comienzan a observarse aproximadamente a partir de los $200^{\circ} \mathrm{C}$. Alrededor de $650^{\circ} \mathrm{C}$ generalmente la estructura interna de las capas de crecimiento tiende a desaparecer, mostrando un aspecto interno uniforme y desarrollándose sistemáticamente pequeños poros redondeados. El número y el tamaño de poros en la estructura de los exoesqueletos se incrementará a medida que aumenta la temperatura de exposición, llegando a transformarse en fisuras, grietas y laminación de la estructura en materiales expuestos a altas temperaturas (Maritan et al., 2007). Cuanto más altas sean las temperaturas a las que se exponen los exoesqueletos, más rápidamente se producirá el deterioro y, en última instancia, la ruptura de los mismas (Claassen, 1998; Villamarzo, 2009; Bonizzoni et al., 2009; Villagrán et al., 2011; Villagrán, 2014).

A nivel macroscópico, los exoesqueletos calcáreos afectados por acción térmica presentan un cambio en la coloración original (Villamarzo, 2009; Villagrán et al., 2011). El proceso de carbonificación identificado en sitios arqueológicos se relaciona con la cocción de los moluscos directamente sobre el fuego, lo que produce el enriquecimiento en carbono de las conchas, que generalmente son cubiertas por una capa de sedimento muy fino de color gris (Gutiérrez Zugasti, 2008a).

\section{MATERIALES Y MÉTODOS}

Ejemplares actuales de Nacella magellanica fueron recolectados por una de las autoras en plataformas de abrasión ubicadas al norte de la ciudad de Puerto Deseado, en el área CNSC (Figura 1). Luego de la recolección los individuos fueron introducidos en agua a $100^{\circ} \mathrm{C}$ durante alrededor de un minuto y posteriormente se extrajo la carne. 
Se seleccionaron siete muestras, cada una de ellas conformada por 20 conchas de Nacella magellanica, las cuales fueron pesadas y luego sometidas a la quema controlada con el fin de reconocer la acción de la termoalteración en los exoesqueletos.

El programa experimental consistió en la quema controlada de las siete muestras de exoesqueletos calcáreos sin carne con una mufla y termocupla digital para obtener mayor control sobre las temperaturas. Las muestras se sometieron a temperaturas sucesivas desde los $0^{\circ} \mathrm{C}$ a los $700^{\circ} \mathrm{C}$. Los siete conjuntos fueron introducidos en el mismo momento en la mufla que se programó para que cada $100^{\circ} \mathrm{C}$ permanezca en la temperatura deseada durante 15 minutos. Una vez extraídas del horno las conchas fueron pesadas para calcular el porcentaje de pérdida de peso producido por la quema.

Se llevó a cabo el análisis estructural, cromático y textural sobre cada una de las muestras. Los exoesqueletos se observaron en una lupa binocular con cámara fotográfica acoplada (x5, x20 y x40 aumentos). Para la realización del análisis cromático, las muestras se compararon con una escala de colores Munsell y se fotografiaron.

A partir del análisis textural se analizó la aparición de cambios en el exoesqueleto y en la morfología de cada una de las conchas expuestas a las distintas temperaturas. Este estudio se realizó con el fin de poder complementar dicha información con las transformaciones identificadas en el color y relacionar estos resultados con las temperaturas involucradas. Las variables texturales consideradas fueron: presencia de fisuras, grietas (longitudinales, transversales y múltiples), fracturas, puntos blancos, descascaramiento /exfoliación y levantamientos de la película superficial.

Entre los parámetros texturales se analizó: la conservación de la dureza, el aspecto del margen o borde (anguloso o redondeado), la cohesividad de los componentes o consistencia (dura, compacta, frágil y/o porosa), la adhesividad, la uniformidad y la aparición de aspecto pulverulento en la superficie externa.

En cuanto a la alteración térmica se clasificó las evidencias en distintos grados: sin alteración, quemado, carbonizado y calcinado. También se registró la situación de la alteración, en el sentido de si las modificaciones afectan a la cara interna y/o externa de la concha, el borde o margen y/o el sector del ápice.

Con el fin de contrastar los resultados del programa inicial se llevaron a cabo cuatro controles experimentales. Se buscó registrar la incidencia del tiempo y la temperatura de exposición al calor. Para ello, cuatro muestras de exoesqueletos fueron sometidas a $100^{\circ} \mathrm{C}, 200^{\circ} \mathrm{C}, 300^{\circ} \mathrm{C}$ y $500^{\circ} \mathrm{C}$ y las modificaciones producto del calentamiento se compararon con los obtenidos inicialmente.

Posteriormente, se estudiaron conjuntos arqueomalacológicos obtenidos a partir de excavaciones sistemáticas en tres concheros en la CNSC y se analizó la presencia de evidencias de termoalteración en los restos. Los resultados obtenidos se compararon con los derivados del programa experimental.

Para los concheros analizados se cuenta con antecedentes del estudio de los materiales antracológicos recuperados en las excavaciones, los cuales fueron integrados en la discusión de este trabajo. Se identificaron diversos taxa de una muestra de carbones de cada sitio siguiendo una curva de riqueza específica (Chabal, 1988, 1990; Badal García, 1992) y su comparación con material de referencia del área de estudio. Se tuvieron en cuenta los 
resultados de un trabajo previo de carbonización experimental de leños del área de estudio en el que se registraron los rasgos diagnósticos postcarbonización a $400^{\circ} \mathrm{C} \mathrm{y} 700^{\circ} \mathrm{C}$. De estos estudios se obtiene una estimación de las temperaturas logradas en los sitios a partir de la presencia de aberturas en radios, vasos y anillos de las maderas empleadas para la combustión (Ciampagna, 2015, 2016).

\section{RESULTADOS}

\subsection{Resultados del análisis cromático y textural}

Muestra 1: $100^{\circ} \mathrm{C}$. A simple vista no se observan cambios morfoestructurales, texturales, ni en la coloración de las conchas. En la observación bajo lupa tampoco se registraron alteraciones. Se preserva la coloración y los rasgos originales del exoesqueleto.

Muestra $2: 200^{\circ} \mathrm{C}$. No se registran cambios morfoestructurales, texturales ni en la coloración de la cara externa de las conchas. En algunos de los ejemplares se observaron escasas microfisuras en el sector de la impresión muscular del molusco sobre la cara interna del exoesqueleto.

A $100^{\circ} \mathrm{C}$ y $200^{\circ} \mathrm{C}$ se preservan los signos de las impresiones musculares, así como la coloración bandeada característica de la especie. El color original de la concha se preserva tanto en la cara externa como en la interna (Figura 3).

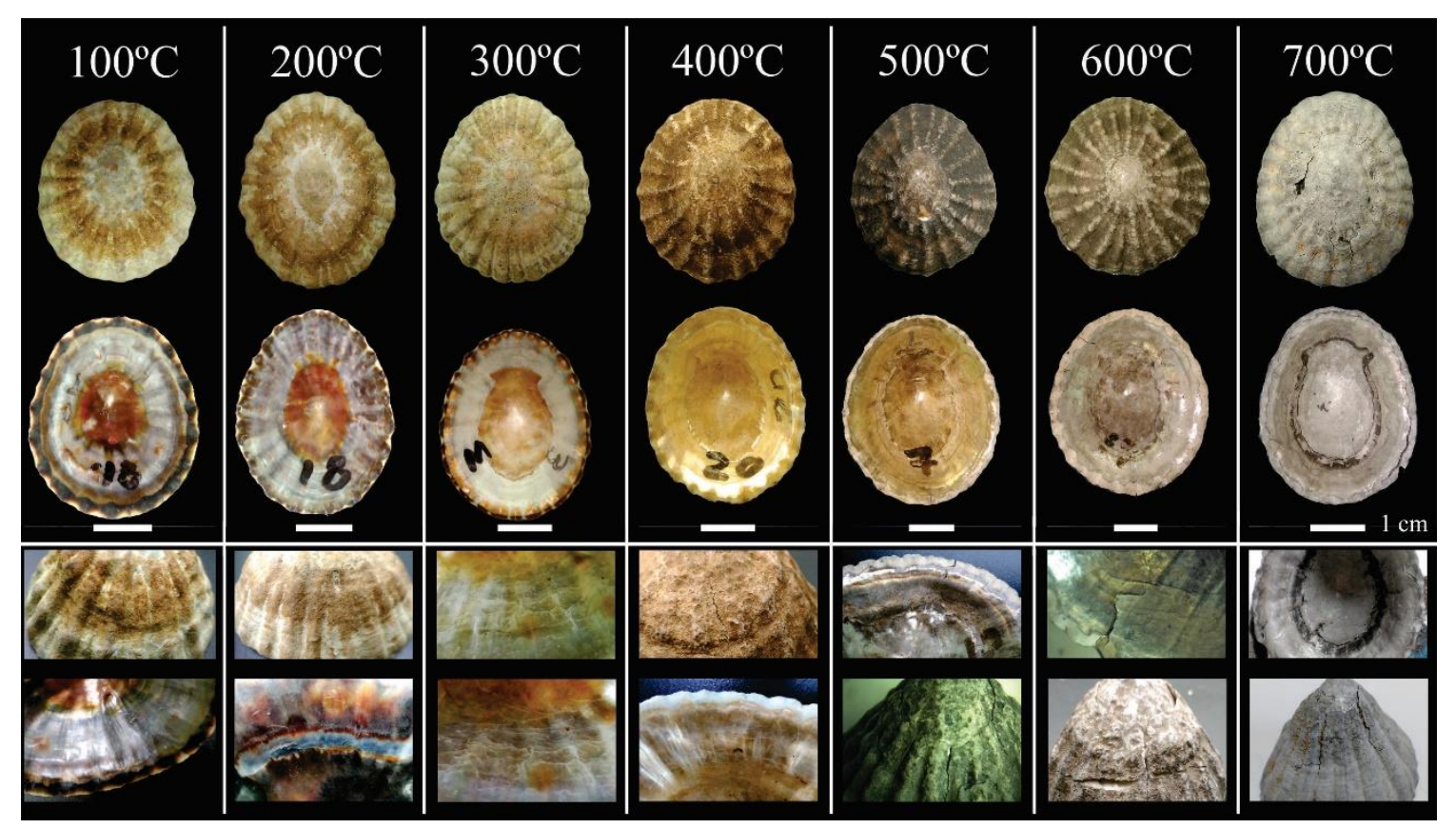

Figura 3. Proceso de modificación de las conchas Nacella magellanica expuestas a temperaturas de entre $100^{\circ} \mathrm{C}$ y $700^{\circ} \mathrm{C}$.

Muestra 3: $300^{\circ} \mathrm{C}$. Se inicia un cambio en el color original del exoesqueleto calcáreo. A esta temperatura las conchas tienden a adquirir un color marrón claro/natural en la superficie externa. Los cambios más notables en la coloración se desarrollan en la cara interna, en la cual la superficie se torna de color natural/beige con mucho brillo (Figura 3). Además, se 
comienzan a perder los signos de las impresiones musculares del gasterópodo. El borde preserva parcialmente el color original en la mayoría de los casos y la zona del ápice (por encima de la impresión muscular) se presenta de color natural/marrón claro con brillo. En la cara interna se desarrollan microfisuras longitudinales, transversales (concéntricas) y múltiples en toda la superficie. Se aprecia un craquelado o reticulado de la capa superficial y en algunos casos fracturas y levantamientos de fragmentos angulares muy pequeños.

Las conchas se encuentran bien preservadas, se distinguen las costillas radiales sin modificaciones y no hay cambios texturales importantes. El borde de las conchas se preserva en todos los casos (no se registran fisuras ni fracturas). Sin embargo, a esta temperatura ya se aprecia un leve debilitamiento de los exoesqueletos y una pérdida de peso, aunque poco significativa (Tabla 1).

Muestra 4: $400^{\circ} \mathrm{C}$. En este caso se acentúan los cambios de coloración que comienzan a desarrollarse a $300^{\circ} \mathrm{C}$. La concha adquiere color marrón claro a oscuro en la superficie externa, en tanto que en la cara interna se desarrolla un color marrón claro/beige en toda la superficie con brillo homogéneo. Un cambio a resaltar es que a $400^{\circ} \mathrm{C}$ el borde en la cara interna cambia de color, hacia el natural, marrón claro o crema y pierde totalmente la coloración original (Figura 3). También es posible delimitar el borde o margen del resto de la estructura a partir de este cambio en su coloración. A esta temperatura la estructura aún conserva su forma compacta. El calentamiento hasta $400^{\circ} \mathrm{C}$ produce un aumento del brillo en la superficie interna de la concha. En la cara externa hay evidencias de exfoliación o descascaramiento en el borde, se desprenden pequeñas escamas en la terminación de las costillas radiales sobre el margen. En el sector del ápice se desarrollan puntos blancos de daño y fisuras finas que remarcan el contorno del ápice, a partir de las cuales se originan fisuras longitudinales entre las costillas radiales, que en algunos casos evolucionan a grietas (Figura 4). En la zona del ápice se registraron evidencias de exfoliación, ya que pequeños fragmentos superficiales se laminan y se desprenden a partir del daño inicial generado por el desarrollo de las fisuras.

En la cara interna se genera un craquelado de la superficie con gran cantidad de fisuras múltiples y largas fisuras concéntricas paralelas al borde. Este craquelado es más pronunciado que en el conjunto expuesto a $300^{\circ} \mathrm{C}$. En el sector de la inserción muscular, donde también se desarrolla esta modificación, fue posible observar bajo lupa la pérdida de pequeños fragmentos superficiales (Figura 4). En este caso igualmente se registra una leve pérdida de peso de la muestra y un debilitamiento de los exoesqueletos posiblemente por el inicio de la pérdida de contenido de humedad debido a la quema (Tabla 1). 


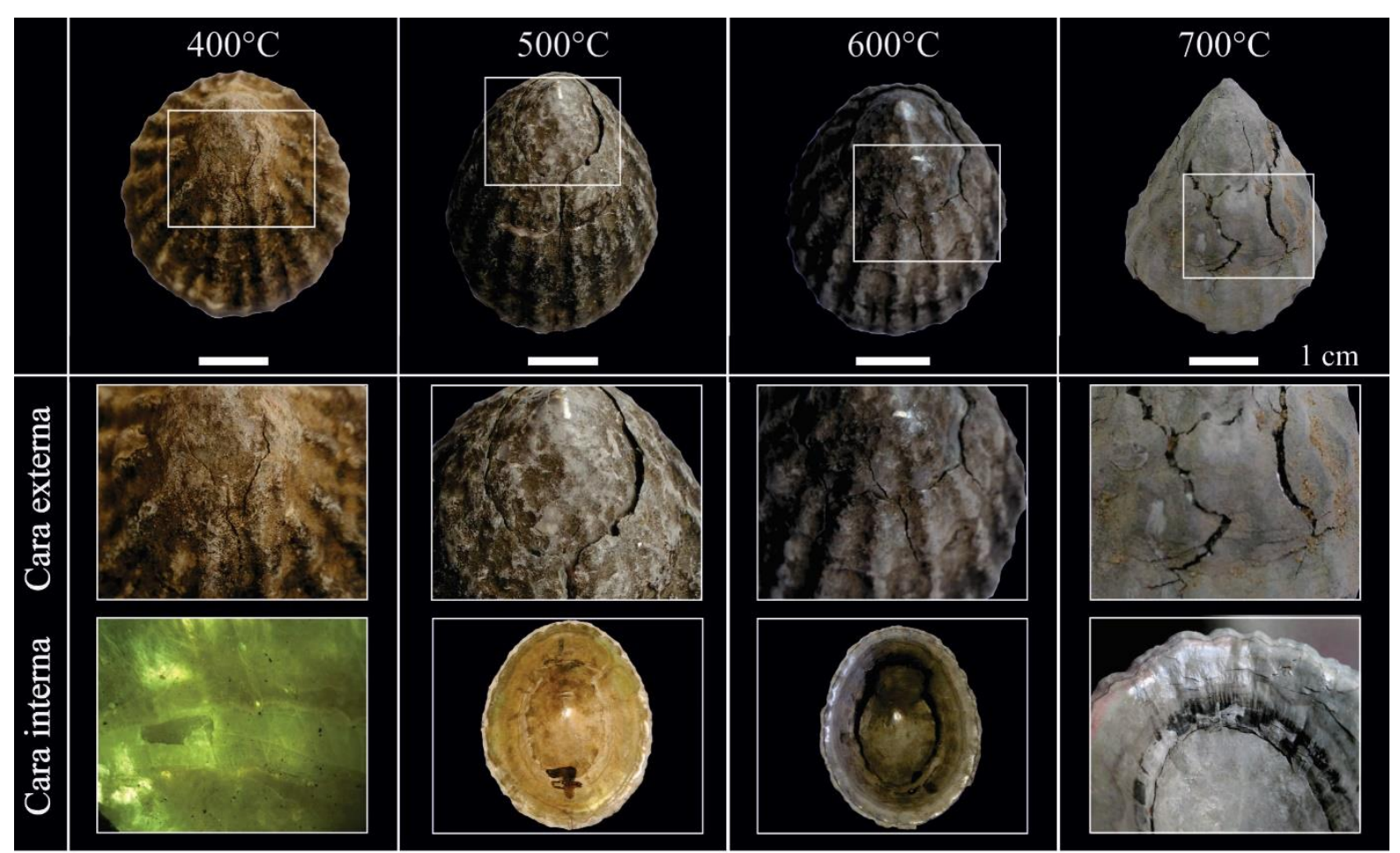

Figura 4. Alteraciones en las conchas de Nacella magellanica expuestas a temperaturas de entre $400^{\circ} \mathrm{C}$ y 700 ${ }^{\circ} \mathrm{C}$.

Muestra 5: $500^{\circ} \mathrm{C}$. A partir de esta temperatura se produce un importante cambio en la coloración externa de las conchas tornándose, a simple vista, de color gris oscuro a negro (Figuras 3 y 4). Hay un oscurecimiento marcado en la coloración de la superficie externa que contrasta con el intervalo de temperatura anterior. Este cambio cromático puede estar relacionado con la pérdida de agua del exoesqueleto y con la carbonización de la matriz orgánica. Los exoesqueletos presentan estado frágil y en algunos los bordes se fracturan y se pierden pequeños fragmentos. La textura externa es porosa.

En casi la totalidad de los ejemplares de la muestra (95\%) se observa un patrón de modificación en la cara externa. Este se caracteriza por la presencia de fisuras en el contorno del ápice (remarcan su forma ovalada) y la presencia de pequeñas fisuras longitudinales, que parten desde las anteriores y se desarrollan entre las costillas radiales (Figura 4). Además, en los laterales de estas fisuras se desarrollan, en algunos casos, fisuras transversales finas y cortas.

En algunas conchas se registraron principios de exfoliación o laminación de la superficie externa, siempre en cercanías del ápice. A partir de la aparición de las fisuras, la superficie alterada comienza a levantarse y se produce la pérdida de fragmentos. En la cara externa también se observaron evidencias de exfoliación en el borde, en el cual pequeñas escamas se desprenden en la terminación de las costillas radiales sobre el margen. Sin embargo, las costillas conservan su apariencia original, aunque las conchas en general se hallan en un estado frágil.

La cara interna de la concha es de color marrón/gris brilloso y este color es homogéneo en toda la superficie, excepto en el borde fino que se vuelve de color blanco/gris claro como 
consecuencia de la calcinación (Figuras 3 y 4). En algunas conchas el sector del borde presenta una fisura que lo delimita, por lo cual se fracturan pequeñas porciones de esta zona.

En la cara interna se observan múltiples microfisuras de la capa superficial y las capas más profundas de la estructura calcárea, así como pequeñas pérdidas de material, principalmente en la zona de la impresión muscular (fragmentos angulares). El sector de la impresión muscular en algunas de las conchas $(n=8)$ se daña y se separa de la estructura. En dos exoesqueletos se observaron largas fisuras paralelas al borde y la presencia de grietas profundas perpendiculares a los bordes, debido a la profundización de fisuras. A $500^{\circ} \mathrm{C}$ las conchas se hallan carbonizadas y el borde calcinado.

Muestra 6: $600^{\circ} \mathrm{C}$. En la cara externa las conchas adquieren color gris en la zona del ápice y hacia los bordes color gris oscuro a negro. En la superficie interna el color es gris claro muy brilloso (con apariencia plateada; Figuras 3 y 4).

La concha en general se vuelve friable y frágil. El margen en todos los casos se presenta de color blanco y calcinado. En algunos exoesqueletos el borde se comienza a separar del resto de la estructura a partir de una fisura profunda que lo delimita claramente en todo el contorno. La aparición de fisuras y en algunos casos de grietas perpendiculares al borde, hace que fragmentos pequeños del margen se desprenden fácilmente.

En la cara externa se acentúa el patrón registrado a $500^{\circ} \mathrm{C}$, se observan las fisuras múltiples con patrón dendrítico en torno al ápice, la aparición de fisuras dendríticas finas en el ápice y múltiples fisuras longitudinales (entre costillas radiales) y transversales de diferente grosor, algunas de ellas llegan a convertirse en grietas. En algunas conchas se desarrollan fisuras cortas paralelas al borde, tanto en la cara externa como en la interna.

Los exoesqueletos en general están muy debilitados. En dos de las conchas se registró la fractura del ápice (este fragmento se desprendió del resto de la estructura, fracturándose en el sector de la impresión muscular). Los exoesqueletos han perdido la humedad, se encuentran frágiles, deshidratados y se fracturan fácilmente. A pesar del debilitamiento y las modificaciones del color y la textura, es posible apreciar la escultura de la concha y las costillas radiales.

Hay evidencias de exfoliación o laminación y pérdida de pequeños fragmentos angulares de la capa calcárea externa que se desarrollan a partir de fisuras. Este hecho se registra en todos los casos en la zona del ápice y en cercanías del mismo. En algunos casos también se observó la pérdida de fragmentos en el sector de finalización de las costillas radiales sobre el borde.

En la cara interna, las conchas presentan fisuras múltiples en distintas direcciones: longitudinales, transversales y cruzadas. Bajo lupa se observa un craquelado profundo de la microestructura y pérdida de fragmentos angulares en capas o láminas que se han fisurado (a $500^{\circ} \mathrm{C}$ estas microfisuras y microfracturas afectaban la capa más superficial y capas más profundas solo en el sector de la impresión muscular). La impresión muscular del molusco se fisura y se desprende notoriamente en pequeños fragmentos en la mayoría de los exoesqueletos. Se registraron grietas perpendiculares al borde de la concha a partir de las cuales se separan fragmentos laminares.

Muestra 7: $700^{\circ} \mathrm{C}$. La coloración se torna gris-blanquecina como consecuencia de la calcinación (Figuras 3 y 4). Esta característica está acompañada por la pérdida de la cohesión interna y el estado muy frágil de la microestructura. La estructura interna de las capas de 
crecimiento tiende a desaparecer y se fracturan partes de los bordes calcinados. La textura de la cara externa es porosa, áspera y pulverulenta, se desprende un fino polvo conformado por la descomposición del $\mathrm{Ca}_{3} \mathrm{Co}$. Se observa un deterioro general de las conchas, una deshidratación total y una alta friabilidad de toda la estructura.

En la cara externa se reconoce bajo lupa un patrón de fisuras y grietas. Las fisuras dendríticas se distribuyen en el sector del ápice y en torno al mismo, y en la mayoría de las conchas también se registra una grieta que resalta la morfología ovalada del ápice. Desde el ápice y hacia los bordes se desarrollan fisuras y en algunos casos grietas entre las costillas radiales, y a su vez fisuras paralelas al borde en el resto de la estructura calcárea, que cortan perpendicularmente a las costillas radiales. Se identificaron fisuras concéntricas paralelas al borde tanto en la cara externa como en la cara interna de la concha (Figura 4).

En el sector del ápice y en la finalización de las costillas radiales en el borde de la concha, se relevaron signos de exfoliación o descascaramiento de la capa superficial. En el ápice la pérdida de fragmentos se genera a partir del levantamiento de material producto de la apertura y daño generado por las fisuras. En dos conchas se produjo el desprendimiento del ápice por fractura, esta es la parte más debilitada del exoesqueleto.

La cara interna presenta color gris claro mate, con algunos sectores con brillo (Figura 4). Macroscópicamente la cara interna posee el color gris mencionado, aunque la línea de la impresión muscular resalta notoriamente al presentarse de color gris oscuro/negro (Figura 4).

En la cara interna se observaron bajo lupa fisuras múltiples, grietas y fisuras paralelas al borde, deslaminación de las capas de crecimiento y fracturas y pérdidas de material. También se relevó en algunos casos la presencia de grietas profundas que se desarrollan en los bordes, paralelas a las costillas radiales. La zona de la impresión muscular se encuentra fisurada, fracturada y con pérdidas de fragmentos angulosos.

El borde posee color gris claro, se halla calcinado y en muchos casos se comienza a separar del resto de la estructura debido a la profundización de la fisura que lo delimita en todo su contorno.

En la Tabla 1 se presenta una síntesis de las modificaciones sufridas por los exoesqueletos expuestos a temperaturas de entre $100^{\circ} \mathrm{C}$ y $700^{\circ} \mathrm{C}$, se consigna el peso inicial y postexposición de cada una de las muestras malacológicas expuestas al calor, así como el color, las características texturales y la descripción de otros aspectos específicos.

\subsection{Controles experimentales}

Control 1: cuatro muestras ( $\mathrm{n}=3$ conchas) fueron colocadas en el horno hasta $\operatorname{los} 100^{\circ} \mathrm{C}$ (se tardó 7 minutos en alcanzar dicha temperatura). Cada 30 minutos se extrajo una muestra por vez, hasta llegar a las 2 horas de permanencia en la mufla. En este caso los exoesqueletos de las cuatro muestras no sufrieron ningún tipo de cambio.

Control 2: cuatro muestras $(n=3)$ fueron colocadas en el horno hasta los $200^{\circ} \mathrm{C}$. Cada 30 minutos se extrajo una por vez, hasta llegar a las 2 horas de permanencia en la mufla. La muestra extraída a los 30 minutos no presenta ningún cambio. Las muestras de este 
experimento control expuestas durante 60,90 y 120 minutos a $200^{\circ} \mathrm{C}$ presentan características similares a aquellas expuestas a $300^{\circ} \mathrm{C}$ en el programa experimental inicial.

Control 3: una muestra de 5 conchas se introdujo en la mufla a $300^{\circ} \mathrm{C}$ y se mantuvo durante 15 minutos. Las conchas expuestas al calor presentan los mismos cambios morfoestructurales, textuales y colorimétricos que aquellas expuestas a $300^{\circ} \mathrm{C}$ en el programa experimental inicial.

Control 4: una muestra de 5 conchas se introdujo en la mufla a $500^{\circ} \mathrm{C}$ y se mantuvo durante 15 minutos. Las conchas expuestas al calor presentan los mismos cambios morfoestructurales, textuales y colorimétricos que aquellas expuestas a la misma temperatura en el programa experimental inicial. 
H. Hammond y M. L. Ciampagna

Estudio experimental de alteración térmica sobre exoesqueletos de moluscos

\begin{tabular}{|c|c|c|c|c|c|c|c|c|}
\hline \multirow{2}{*}{ 吾 } & \multirow{2}{*}{$\begin{array}{l}\text { Temperatur } \\
\quad \text { ade } \\
\text { exposición }\end{array}$} & \multirow{2}{*}{$\begin{array}{l}\text { Peso inicial } \\
\text { (gramos) }\end{array}$} & \multirow{2}{*}{$\begin{array}{l}\text { Peso post- } \\
\text { exposición } \\
\text { (gramos) }\end{array}$} & \multicolumn{2}{|r|}{ Color } & \multicolumn{2}{|c|}{ Textura } & \multirow{2}{*}{ Descripción } \\
\hline & & & & $\begin{array}{c}\text { Cara } \\
\text { externa }\end{array}$ & $\begin{array}{c}\text { Cara } \\
\text { interna }\end{array}$ & $\begin{array}{c}\text { Cara } \\
\text { externa }\end{array}$ & Cara interna & \\
\hline 1 & $100^{\circ} \mathrm{C}$ & 90 & 90 & Original & Original & $\begin{array}{l}\text { Compactal } \\
\text { Porosa }\end{array}$ & $\begin{array}{l}\text { Finalapariencia } \\
\text { vidriada }\end{array}$ & $\begin{array}{c}\text { Sin cambios, superficies continuas/Sin } \\
\text { alteración térmica }\end{array}$ \\
\hline 2 & $200^{\circ} \mathrm{C}$ & 85,06 & 85 & Original & Original & $\begin{array}{l}\text { Compactal } \\
\text { Porosa }\end{array}$ & $\begin{array}{l}\text { Fina/apariencia } \\
\text { vidriada, brillosa }\end{array}$ & $\begin{array}{l}\text { Superficies continuas/Primeros signos de } \\
\text { alteración: microfisuras en zona de } \\
\text { impresión muscular }\end{array}$ \\
\hline 3 & $300^{\circ} \mathrm{C}$ & 71,1 & 70,9 & $\begin{array}{l}\text { Marrón } \\
\text { clarol } \\
\text { Natural }\end{array}$ & $\begin{array}{l}\text { Natural/ Beige con } \\
\text { mucho brillo }\end{array}$ & $\begin{array}{l}\text { Compactal } \\
\text { Porosa }\end{array}$ & $\begin{array}{l}\text { Fina/apariencia } \\
\text { vidriada, brillosa }\end{array}$ & $\begin{array}{l}\text { Superficie interna con alto brillo, } \\
\text { craquelado superficial, cambios iniciales de } \\
\text { color en ambas caras/Quemado }\end{array}$ \\
\hline 4 & $400^{\circ} \mathrm{C}$ & 92,3 & 91,3 & $\begin{array}{l}\text { Marrón/ } \\
\text { Marrón } \\
\text { oscuro }\end{array}$ & $\begin{array}{l}\text { Natural/beige con } \\
\text { mucho brillo. Borde } \\
\text { natural/crema }\end{array}$ & $\begin{array}{l}\text { Compactal } \\
\text { Porosa }\end{array}$ & $\begin{array}{l}\text { Fina/apariencia } \\
\text { vidriada, brillosa, } \\
\text { craquelada }\end{array}$ & $\begin{array}{c}\text { Craquelado superficial pronunciado en cara } \\
\text { interna, cambio de color del bordel } \\
\text { Quemado }\end{array}$ \\
\hline 5 & $500^{\circ} \mathrm{C}$ & 97,33 & 95,07 & $\begin{array}{l}\text { Gris } \\
\text { oscuro/ } \\
\text { Negro }\end{array}$ & $\begin{array}{l}\text { Marrón/ Gris } \\
\text { brilloso. Borde } \\
\text { gris/blanco }\end{array}$ & $\begin{array}{l}\text { Frágil/ } \\
\text { Porosa }\end{array}$ & $\begin{array}{l}\text { Apariencia } \\
\text { vidriada, brillosa, } \\
\text { craquelada, } \\
\text { escamosa }\end{array}$ & $\begin{array}{c}\text { Craquelado profundo cara interna, cambio } \\
\text { de color del borde, se deprende la capa } \\
\text { superficial de la impresión muscularl } \\
\text { Carbonizado, borde calcinado }\end{array}$ \\
\hline 6 & $600^{\circ} \mathrm{C}$ & 84,58 & 81,2 & $\begin{array}{l}\text { Gris/Gris } \\
\text { oscuro }\end{array}$ & $\begin{array}{l}\text { Gris claro muy } \\
\text { brilloso. Borde } \\
\text { gris/Blanco }\end{array}$ & $\begin{array}{l}\text { Frágil } \\
\text { /Porosa }\end{array}$ & $\begin{array}{l}\text { Apariencia } \\
\text { vidriada, brillosa, } \\
\text { escamosa }\end{array}$ & $\begin{array}{l}\text { Craquelado profundo cara interna, cambio } \\
\text { de color del borde/Carbonizado-calcinado }\end{array}$ \\
\hline 7 & $700^{\circ} \mathrm{C}$ & 76,63 & 73,4 & $\begin{array}{l}\text { Gris claro/ } \\
\text { Blanque- } \\
\text { cino }\end{array}$ & $\begin{array}{l}\text { Gris claro mate con } \\
\text { brillos localizados, } \\
\text { impresión muscular } \\
\text { gris oscura/Negra }\end{array}$ & $\begin{array}{l}\text { Muy } \\
\text { frágil/Poros } \\
\text { a/Superficie } \\
\text { externa } \\
\text { pulverulenta }\end{array}$ & $\begin{array}{l}\text { Porosa, escamosa, } \\
\text { deslaminación; } \\
\text { pérdida de } \mathrm{Co}_{3} \mathrm{Ca}\end{array}$ & $\begin{array}{c}\text { Superficie fisurada, agrietada, granular, con } \\
\text { fracturas y pérdidas de borde y } \\
\text { deslaminación de la microestructura por } \\
\text { pérdida de cohesión interna de la } \\
\text { microestructura/Calcinado }\end{array}$ \\
\hline
\end{tabular}

Tabla 1. Síntesis de las modificaciones en exoesqueletos de Nacella magellanica expuestos a temperaturas de entre $100^{\circ} \mathrm{C}$ y $700^{\circ} \mathrm{C}$ 


\subsection{ESTUDIO COMPARATIVO DE LOS RESULTADOS EXPERIMENTALES CON LAS MUESTRAS ARQUEOMALACOLÓGICAS DE CONCHEROS}

El objetivo final de este trabajo es establecer características diagnósticas que permitan distinguir rasgos del calentamiento intencional en conchas patelliformes de sitios arqueológicos. Para ello se analizaron muestras arqueomalacológicas de Nacella magellanica de tres concheros ubicados en la CNSC; ellos son: Las Hormigas, el Sitio 112 y el Sitio 160 (Figura 1; Ciampagna, 2015; Hammond, 2015).

Se realizaron los estudios cromáticos, estructurales y texturales de los exoesqueletos de moluscos arqueológicos. En estos conjuntos hay que tener en cuenta que existen otros procesos tafonómicos que pueden haber afectado la preservación de los restos, como por ejemplo, la incidencia del proceso de corrosión, abrasión, bioerosión, así como las condiciones geoquímicas de la matriz sedimentaria del depósito (Hammond, 2013). A continuación se presenta una breve caracterización de los concheros considerados.

\subsubsection{Las Hormigas}

Se emplaza en un manto eólico sobre una terraza holocénica y posee una datación radiocarbónica de 370 \pm 40 años AP (LP-2504, carbón vegetal; 488-312 años calib. AP). Se trata de un conchero lenticular con alta densidad de materiales arqueológicos (Hammond, 2015). Se realizó el análisis antracológico de carbones recuperados en la excavación (Ciampagna, 2015). En el cuadrante A $\left(0,25 \mathrm{~m}^{2}\right)$ se identificaron tres taxa: Schinus con una densidad relativa de 71,8\% ( $n=18)$, seguido por Senecio/Baccharis $(20 \%$; $n=5)$ y Adesmia e indeterminables (4\%; $\mathrm{n}=1$ en ambos casos). En el cuadrante $\mathrm{C}$ se identificaron tres taxa. Predominó Schinus con una densidad relativa del $44 \%(\mathrm{n}=15)$ y en menor densidad relativa Atriplex/Suaeda, cf. Lycium e indeterminables. Se registró una mayor densidad de carbones provenientes de maderas semiduras como Schinus, acompañada de leñosas blandas buenas iniciadoras del fuego (i.e. Senecio/Baccharis). Los carbones dispersos darían cuenta de uno o más eventos intensos, con producción de brasa debido al predominio de Schinus. En relación a las temperaturas que pudo alcanzar la combustión de estas maderas, no se observaron caracteres diagnósticos de altas temperaturas (Ciampagna, 2015, 2016).

\subsubsection{Sitio 112}

El conchero se emplaza sobre un manto eólico en deflación. Se cuenta con un fechado

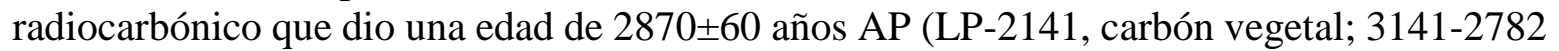
años calib. AP). Se determinaron los carbones asociados a la lente de materiales arqueológicos y se identificó Schinus con una densidad relativa del $88 \%(\mathrm{n}=15)$ seguido por Senecio/Baccharis e indeterminables (menos del 5\%; $n=1$ ). Es relevante el alto porcentaje de densidad relativa de carbones de Schinus, ya que su madera produce brasa y tiene alto poder 
calórico. Sin embargo, no se registraron en los carbones aberturas diagnósticas de temperaturas por encima de $\operatorname{los} 400^{\circ} \mathrm{C}$ (Ciampagna, 2015, 2016). La lente del conchero se ubicaba sobre una capa de sedimento carbonizado y la totalidad del conjunto arqueológico presentaba adherida una fina capa de cenizas y carbonatos de color gris.

\subsubsection{Sitio 160}

El conchero se emplaza en una duna afectada por deflación. Se cuenta con dos dataciones radiocarbónicas, ambas realizadas sobre carbón vegetal asociado a dos lentes de materiales arqueológicos superpuestas. El fechado de la lente inferior arrojó una edad de $1260 \pm 80$ años (LP-3091; 1279-965 años calib. AP), en tanto que la lente superior se dató en 370 \pm 50 años AP (LP-2507; 492-306 años calib. AP). Se analizaron los carbones provenientes de la lente superior la cual se dividió en porción superior e inferior debido a la potencia de la misma. En la porción superior se identificó un solo taxa: Schinus, con una densidad relativa del $95 \%$ $(\mathrm{n}=21)$ y el $5 \%$ restante $(\mathrm{n}=1)$ fue indeterminado. En la porción inferior, se identificaron Schinus con el $96 \%$ de densidad relativa $(n=24)$ y Senecio/Baccharis $(4 \% ; n=1)$. En esta última, el $80 \%(\mathrm{n}=20)$ de los carbones de Schinus presentó aberturas en vasos y radios, mientras que el $8 \%(\mathrm{n}=2)$ presentó aberturas en vasos, radios y anillos. Este último carácter sería diagnóstico de que el fuego alcanzó temperaturas mayores a los $400^{\circ} \mathrm{C}$ (Ciampagna, 2015).

\subsection{Resultados del estudio de los restos arqueomalacológicos de concheros}

En la Tabla 2 se presentan los resultados del análisis de los materiales arqueomalacológicos. Se analizaron 24 conchas de Nacella magellanica recuperadas en el sitio Las Hormigas. En la cara externa estas presentan color marrón/marrón claro en toda la superficie (Figura 5). En general no poseen alteraciones como fisuras, grietas, puntos blancos o exfoliación. Sin embargo, un exoesqueleto presenta gran parte de la cara externa de color gris claro y además una fisura de morfología oval en torno al ápice (vista bajo lupa binocular). En la cara interna se relevaron fisuras múltiples y pérdida de pequeños fragmentos angulares de la capa calcárea superficial. En un caso se observó la descamación o exfoliación del borde externo en la finalización de las costillas radiales.

La cara interna de las conchas preserva parcialmente el color original, con brillo, aunque en muchos casos la superficie se encuentra carbonatada. En todas las conchas el borde preserva parcialmente el color original y se encuentra completo. En la cara interna se observó la presencia de microfisuras longitudinales, trasversales (paralelas al margen y en dos casos perpendiculares al margen) y fisuras múltiples que conforman un reticulado superficial inicial o craquelado abierto. En la mayoría de los casos el sector de la impresión muscular del molusco presenta fisuras. En diversas conchas se han fisurado y desprendido fragmentos angulares muy pequeños de la capa calcárea superficial.

En observaciones bajo lupa binocular se registraron evidencias de bioerosión, marcas de raíces y carbonatación en la superficie interna de diversos exoesqueletos. La acción de agentes biológicos y geoquímicos altera la estructura carbonática de las conchas a través de 
procesos como la descalcificación y la biodegradación, que pueden generar el debilitamiento y en ocasiones el aumento del índice de fragmentación de los conjuntos (Gutiérrez Zugasti, 2008a).

Para el Sitio 112 se analizaron 12 exoesqueletos de Nacella magellanica (Tabla 2). Todos presentan adherida una capa de cenizas y sedimento limoso de color gris/gris oscuro. En la cara externa las conchas presentan color marrón (estas fueron lavadas y se extrajo la adherencia), y una textura compacta y muy porosa. En la superficie externa los exoesqueletos no presentan ningún tipo de daño (Figura 5).

En la cara interna y en el borde los exoesqueletos preservan parcialmente el color original con mucho brillo. El margen se conserva en todos los ejemplares y no presenta fisuras ni fracturas. En la superficie interna la mayoría de las conchas presentan microfisuras superficiales en el sector de la impresión muscular. Se registraron además microfisuras longitudinales, transversales (largas fisuras paralelas al borde) y múltiples en el resto de la superficie interna en diversas conchas. En seis casos este reticulado es profundo, superando la capa superficial. En la mayoría de los ejemplares se identificó la fractura y pérdida de pequeños fragmentos angulares superficiales principalmente en el sector de la impresión muscular.

En este caso se relevaron evidencias de carbonatación en la superficie interna de las conchas aunque localizada principalmente en las zonas de fisuras y los bordes donde se produjo la fractura y pérdida de fragmentos calcáreos superficiales. En seis conchas las fisuras paralelas al borde son muy notorias.

Se analizó un total de diez exoesqueletos recuperados en el Sitio 160 (Figura 5 y Tabla 2). La cara externa de las conchas presenta color marrón claro y en algunos casos también se observaron manchas negras de carbón. La superficie externa no presenta signos de daños por alteración térmica, la mayoría de las conchas presentan textura compacta y superficie porosa.

En seis exoesqueletos la cara interna presenta color natural/beige. En estas el borde fino es de color natural/marrón claro y es posible delimitarlo del resto de la estructura debido al cambio en la coloración. Además, el sector de la impresión muscular presenta color marrón y se resalta claramente del resto de la superficie. Estas conchas presentan también una fina capa de carbonatos depositada en la cara interna. En los restantes cuatro exoesqueletos la cara interna y el borde preservan parcialmente el color original, y poseen signos de carbonatación leve.

En la cara interna se registró la presencia de microfisuras múltiples y fisuras longitudinales y cruzadas paralelas al borde, además todas las conchas presentan signos de exfoliación o pérdida de fragmentos superficiales. Cinco de las seis conchas que presentan cambio en la coloración del borde han perdido fragmentos muy pequeños del mismo.

En este caso seis exoesqueletos presentarían evidencias de exposición de hasta aproximadamente $400^{\circ} \mathrm{C}$ de temperatura, sin embargo la otra parte del conjunto presenta evidencias de haber estado expuesto a no más de $300^{\circ} \mathrm{C}$. Todos los exoesqueletos analizados recuperados en el Sitio 160 presentan marcas de raíces en la cara interna, que se destacan además debido a la depositación superficial de carbonatos.

En los tres conjuntos arqueomalacológicos estudiados se preserva la escultura de las conchas caracterizada por la presencia de costillas radiales y margen festoneado. 
H. Hammond y M. L. Ciampagna

Estudio experimental de alteración térmica sobre exoesqueletos de moluscos

\begin{tabular}{|c|c|c|c|c|c|c|c|}
\hline \multirow[b]{2}{*}{ Conchero } & \multirow{2}{*}{$\begin{array}{l}\text { Nde } \\
\text { conchas } \\
\text { analizadas }\end{array}$} & \multicolumn{2}{|r|}{ Color } & \multicolumn{2}{|c|}{ Textura } & \multirow[b]{2}{*}{ Descripción } & \multirow{2}{*}{$\begin{array}{c}\text { Probable } \\
\text { temperatura } \\
\text { de exposición }\end{array}$} \\
\hline & & $\begin{array}{c}\text { Cara } \\
\text { externa }\end{array}$ & $\begin{array}{c}\text { Cara } \\
\text { interna }\end{array}$ & $\begin{array}{c}\text { Cara } \\
\text { externa }\end{array}$ & $\begin{array}{c}\text { Cara } \\
\text { interna }\end{array}$ & & \\
\hline $\begin{array}{c}\text { Las } \\
\text { Hormigas }\end{array}$ & 24 & $\begin{array}{l}\text { Marrón/ } \\
\text { marrón } \\
\text { claro }\end{array}$ & $\begin{array}{l}\text { Pérdida parcial del } \\
\text { color original } \\
\text { (hacia tonos } \\
\text { marrones) }\end{array}$ & $\begin{array}{c}\text { Compactal } \\
\text { Porosa }\end{array}$ & $\begin{array}{c}\text { Final } \\
\text { apariencia } \\
\text { vidriada, brillosa, } \\
\text { superficie } \\
\text { carbonatada }\end{array}$ & $\begin{array}{c}\text {-Superficie interna con brillo, fisuras } \\
\text { múltiples, craquelado superficial. } \\
\text {-Quemado. }\end{array}$ & Hasta $300^{\circ} \mathrm{C}$ \\
\hline Sitio 112 & 12 & Marrón & $\begin{array}{c}\text { Pérdida parcial del } \\
\text { color original } \\
\text { (hacia tonos } \\
\text { marrones) }\end{array}$ & $\begin{array}{c}\text { Compactal } \\
\text { Porosa }\end{array}$ & $\begin{array}{c}\text { Final } \\
\text { apariencia } \\
\text { vidriada, brillosa, } \\
\text { partes } \\
\text { carbonatadas }\end{array}$ & $\begin{array}{c}\text {-Superficie interna con brillo, fisuras } \\
\text { múltiples, carbonatación entre } \\
\text { fisuras y bordes fracturados, } \\
\text { craquelado profundo en seis. } \\
\text {-Quemado. }\end{array}$ & Hasta $300^{\circ} \mathrm{C}$ \\
\hline Sitio 160 & 10 & $\begin{array}{l}\text { Marrón/ } \\
\text { marrón } \\
\text { claro }\end{array}$ & $\begin{array}{l}n=4: \text { Pérdida } \\
\text { parcial del color } \\
\text { original (hacia } \\
\text { tonos marrones) } \\
n=6: \text { pérdida total } \\
\text { del color original } \\
\text { (natural/ beige) }\end{array}$ & $\begin{array}{c}\text { Compactal } \\
\text { Porosa }\end{array}$ & $\begin{array}{c}\text { Final } \\
\text { apariencia } \\
\text { vidriada brillosa } \\
\text { en } 4 \text { lapas; } 6 \\
\text { ejemplares con } \\
\text { superficie } \\
\text { carbonatada }\end{array}$ & $\begin{array}{c}\text {-Superficies internas con fisuras } \\
\text { múltiples. } \\
\text {-Seis conchas con signos de } \\
\text { exposición a altas temperaturas } \\
\text { (cambio de color en cara interna y en } \\
\text { borde). } \\
\text {-Marcas de raíces. }\end{array}$ & Hasta $400^{\circ} \mathrm{C}$ \\
\hline
\end{tabular}

Tabla 2. Síntesis de las características colorimétricas, texturales y particularidades de los exoesqueletos de Nacella magellanica procedentes de concheros en la CNSC. 


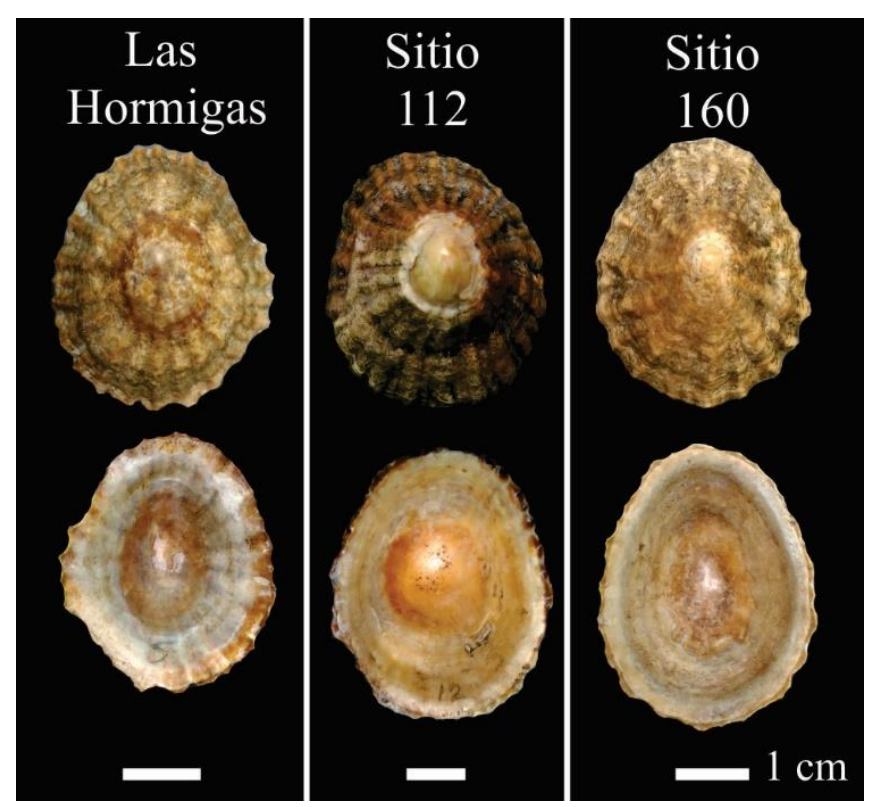

Figura 5. Conchas de Nacella magellanica procedentes de los concheros considerados en este trabajo.

\section{DISCUSIÓN}

\subsection{Síntesis del programa experimental}

Los datos registrados pueden ser interpretados de la siguiente manera:

- En las muestras expuestas a $100^{\circ} \mathrm{C}$ no se registraron cambios morfoestructurales, ni mediante la observación a simple vista ni con lupa binocular.

- A $200^{\circ} \mathrm{C}$ se identificaron escasas microfisuras en el sector de la impresión muscular del exoesqueleto (zona de debilidad). Posiblemente la estructura calcárea compacta, sólida y relativamente gruesa que presentan las conchas es resistente a estas temperaturas.

- A $300^{\circ} \mathrm{C}$ son perceptibles microfisuras múltiples en la cara interna de la concha. La aparición de fisuras es el resultado de la pérdida de agua durante la combustión de la matriz orgánica (Gaffey et al., 1991; Villagrán, 2014).

- Microfracturas con pérdida de material superficial se observan a partir de $300^{\circ} \mathrm{C}$.

- A $400^{\circ} \mathrm{C}$ se produce la pérdida del color original del borde o margen de la concha.

- A $500{ }^{\circ} \mathrm{C}$ la presencia de fisuras y agrietamientos aumenta, hay evidencias de exfoliación o descascaramiento de fragmentos de la microestructura y quebraduras del borde.

- Las alteraciones físicas, junto con la combustión de la matriz orgánica y mineral que provoca un oscurecimiento general de la concha suceden alrededor de $500{ }^{\circ} \mathrm{C}$, temperatura a partir de la cual la estructura calcárea comienza un proceso de deterioro general notable.

- A $500^{\circ} \mathrm{C}$ se desarrolla un patrón caracterizado por la presencia de fisuras en el contorno del ápice y pequeñas fisuras longitudinales, que parten desde las anteriores y se desarrollan entre 
las costillas radiales. Además, en los laterales de estas fisuras longitudinales se desarrollan, en algunos casos, fisuras transversales finas y cortas. Este patrón se acentúa a medida que aumenta la temperatura de exposición.

- A $600^{\circ} \mathrm{C}$ se dio la fractura y desprendimiento del ápice en algunas de las conchas, el desarrollo de fisuras dendríticas en el ápice, grietas perpendiculares al borde y el desarrollo de fisuras paralelas al borde, tanto en la cara externa como en la interna.

- A $700^{\circ} \mathrm{C}$ se generan fracturas múltiples, agrietamientos longitudinales y transversales y roturas en el borde. Los exoesqueletos presentan un estado friable y frágil, se separan finas capas o láminas que conforman la microestructura.

- La coloración marrón claro/beige de los exoesqueletos indica que la temperatura alcanzada fue de entre $300^{\circ} \mathrm{C}$ y $400^{\circ} \mathrm{C}$.

- Los exoesqueletos carbonizados de color gris oscuro/negro indican que el calentamiento alcanzó los $500^{\circ} \mathrm{C}$.

- Las conchas de color gris claro a blanco fueron expuestas a temperaturas por encima de los $600^{\circ} \mathrm{C}$.

- A temperaturas superiores a $600^{\circ} \mathrm{C}$ se evidencian cambios estructurales y morfológicos: roturas del margen y exfoliación de la microestructura.

- Macroscópicamente en las muestras expuestas a $600^{\circ} \mathrm{C}$ la textura superficial presenta un aspecto friable, reseco y de color mate con puntos de brillo.

- Con el aumento de la temperatura las conchas tienden a destruirse y la estructura calcárea se desarticula $\left(\right.$ a $700^{\circ} \mathrm{C}$ y por encima de esta temperatura).

- En general hay un oscurecimiento y una degradación del color de las conchas que va desde el color original hacia el marrón, luego gris oscuro a negro y por último al gris claro/blanquecino. A su vez a temperaturas de entre $100^{\circ} \mathrm{C}$ y $400^{\circ} \mathrm{C}$ el interior de la concha logra un aspecto muy brilloso; el cual se desvanece a temperaturas superiores.

- Las muestras expuestas a $700^{\circ} \mathrm{C}$ adquieren una textura friable y pulverulenta por la destrucción de la estructura carbonática y se produce el desprendimiento de $\mathrm{Co}_{3} \mathrm{Ca}$ en forma de polvo fino.

- A medida que aumenta la temperatura de exposición al calor se acrecienta la fragilidad del exoesqueleto calcáreo. Esto lleva a que la estructura se fracture cada vez en un mayor número de fragmentos. Este hecho en los casos arqueológicos puede dificultar la identificación anatómica y taxonómica de los moluscos, ya que la fragmentación disminuye la identificabilidad de los restos (Gutiérrez Zugasti, 2008a y b).

- Bajo las diferentes temperaturas a las que se expuso los materiales, en todas las muestras se preservaron las características de la ornamentación y escultura de las conchas.

- La pérdida de peso por exposición al calor se registró a partir del conjunto expuesto a $300^{\circ} \mathrm{C}$. Sin embargo, la pérdida es de solo unos pocos gramos (Tabla 1).

- Los controles permitieron corroborar que las muestras sometidas durante un tiempo corto (15 minutos) a una temperatura alta $\left(200^{\circ} \mathrm{C}, 300^{\circ} \mathrm{C}, 500^{\circ} \mathrm{C}\right)$ presentan rasgos de termoalteración similar a las muestras sometidas a un ascenso de la temperatura gradual prolongado en el tiempo (programa experimental). 


\subsection{Discusión de los resultados del programa experimental y las muestras arqueomalacológicas}

A partir del programa experimental se logró identificar diversos rasgos diagnósticos en los exoesqueletos calcáreos de moluscos patelliformes expuestos a diferentes temperaturas. Estas transformaciones se relacionan principalmente con cambios en la coloración, modificaciones texturales, daños estructurales y un leve descenso paulatino del peso de las muestras a medida que estas se exponen a temperaturas más elevadas. Los cambios registrados fueron apreciados claramente a partir de los $300^{\circ} \mathrm{C}$, temperatura a la cual se registraron de forma notoria las modificaciones en la coloración y el desarrollo de microfisuras contiguas en la superficie interna de las conchas.

El estudio comparativo de los tres conjuntos arqueomalacológicos y de los resultados obtenidos a partir del programa experimental permitió inferir que en los concheros Las Hormigas y el Sitio 112 las conchas no habrían estado expuestas a temperaturas superiores a $300^{\circ} \mathrm{C}$ de acuerdo a las características colorimétricas, texturales y a los daños registrados. En el Sitio 160 a partir de los rasgos diagnósticos identificados consideramos que parte del conjunto podría haber estado expuesto a temperaturas de hasta alrededor de $400^{\circ} \mathrm{C}$ (Tabla 2).

A partir de los estudios antracológicos de carbones recuperados en concheros (Ciampagna, 2015, 2016), es posible discutir las probables temperaturas que habrían alcanzado las áreas de combustión en los sitios. Como se mencionó, entre las leñas combustibles de los concheros analizados, Schinus, y en menores proporciones Senecio/Baccharis presentan la mayor ubicuidad porcentual, es decir están presentes en los tres sitios. La mayor densidad porcentual de carbones fue identificada como Schinus, su madera se caracteriza por presentar una alta densidad y dureza, la capacidad de producción de brasa y un alto poder calorífico (Ciampagna, 2015, 2016; Cardoso et al., 2015). En cambio, Senecio/Baccharis se caracterizan por el rápido encendido (ricos en resinas) y corta duración del fuego, por lo que podrían haber sido leñas empleadas para iniciar la combustión. Esta combinación de maderas más densas y duras con otras más blandas podría sugerir algunas de las prácticas de manejo del fuego en estos sitios por parte de las poblaciones pasadas.

Por otra parte, el análisis de los rasgos postcarbonización de los restos antracológicos apoya los resultados obtenidos del estudio comparativo entre los resultados del programa experimental y el análisis de los restos arqueomalacológicos recuperados en los concheros. En los sitios 112 y Las Hormigas no se registraron aberturas en vasos, radios y anillos en carbones de Schinus que son diagnósticos de temperaturas por encima de los $400^{\circ} \mathrm{C}$ (Ciampagna, 2015, 2016). En cambio, en la lente del Sitio 160 se identificaron aberturas en vasos y radios, y en anillo en el 4,2\% de los carbones analizados, evidencias que señalan temperaturas por encima de los $400^{\circ} \mathrm{C}$. En este sentido, es posible que algún sector del área de combustión alcanzara mayor temperatura que la registrada para parte del conjunto de los restos malacológicos analizados (Tabla 2), o bien que estas diferencias entre los indicadores de temperatura de carbones y de restos arqueomalacológicos se deban a diversas variables, entre las que podría mencionarse la posibilidad de que los exoesqueletos de moluscos hayan entrado en contacto con las brasas y no en contacto directo con el fuego. Otra posibilidad es que se hayan producido en el sitio procesos de reencendido en el área de combustión que 
podrían estar relacionados con la presencia de signos de alteración térmica a temperaturas elevadas de los exoesqueletos de moluscos como se interpretó en este caso.

Hay que tener en cuenta que en todos los casos los concheros analizados en este trabajo se encuentran emplazados a cielo abierto y que las condiciones ambientales de la costa patagónica, donde predominan las condiciones frías, áridas y ventosas, podrían haber influido de manera importante en las temperaturas máximas alcanzadas por las maderas identificadas en los sitios arqueológicos.

Por otro lado, la incidencia de la alteración térmica de las conchas variará según diversos factores intrínsecos como la morfología, la microestructura, el grosor, la ornamentación, el tamaño y la resistencia del exoesqueleto calcáreo. Otra variable a considerar es la completitud del exoesqueleto, en el sentido de si este se encuentra completo, fragmentado o se tiene solo un fragmento (Hammond 2015), lo que puede afectar en la incidencia o las consecuencias del daño térmico. Además, el grado de los daños se puede relacionar con diversos factores extrínsecos como la intensidad y duración del calentamiento, el nivel de humedad de los materiales o a factores climático-ambientales (Gaffey et al., 1991).

Las modificaciones registradas en las conchas producto de la alteración térmica en sitios arqueológicos pueden ser consecuencia de tareas de preparación, cocción y consumo de los moluscos como alimento. Sin embargo, estas alteraciones pueden tener otros orígenes, por ejemplo, posteriormente al consumo de la carne los exoesqueletos pueden ser desechados en las áreas de combustión por razones higiénicas y sufrir nuevamente la exposición al calor; o pueden caer accidentalmente al fuego; o bien sufrir modificaciones producto de empleo como combustible. Como se mencionó, las áreas de combustión también pueden sufrir procesos de reencendido, lo que podría generar nuevos daños en los materiales arqueológicos expuestos al fuego. En este sentido, los procesos de encendido, mantenimiento, uso y apagado del fuego en las áreas de combustión de concheros pueden ser sucesos complejos de estudiar y de diferenciar. Sin embargo, analizar las características de los conjuntos arqueomalacológicos, a fin de determinar si existieron eventos de exposición térmica, así como las alteraciones de los restos y posibles trazas distintivas sobre las superficies calcáreas nos permite discutir acerca del uso de las áreas de combustión, la utilización del fuego y los combustibles vegetales, y sobre las posibles prácticas de manejo de los alimentos animales por los grupos cazadores recolectores.

\subsection{Consideraciones finales}

Los estudios realizados permitieron identificar modificaciones y patrones de alteración como consecuencia del tratamiento térmico (calentamiento) de los exoesqueletos calcáreos de moluscos patelliformes. El reconocimiento de este tipo de rasgos en los materiales experimentales puede servirnos para interpretar el uso posible de las áreas de combustión en los sitios arqueológicos y las temperaturas probables a las que estuvieron expuestos los recursos malacológicos en el pasado. En este sentido, a futuro es necesario realizar nuevos trabajos experimentales en el campo y considerar diversas variables (distintos tipos de combustibles, variables ambientales y climáticas, sustratos, etc.) que puedan influir en la incidencia de modificaciones o daños generados por termoalteración sobre los restos malacológicos. 
Dado que las conchas de los moluscos varían en forma, tamaño y mineralogía, es importante seguir desarrollando colecciones experimentales e incluir una mayor diversidad de especies (Villagrán, 2014), para identificar patrones de referencia que puedan ser utilizados para analizar el registro arqueológico y que nos permitan evaluar las posibles causas de las termoalteraciones.

Finalmente, esperamos que los resultados de este trabajo sean útiles para el estudio de restos arqueomalacológicos recuperados en sitios costeros de otras regiones. Estos análisis proveen indicadores para evaluar por ejemplo, cuestiones tafonómicas y de preservación de los conjuntos; la funcionalidad de las áreas de combustión, así como las probables temperaturas alcanzadas por los fuegos; pueden aportar datos para discutir índices de fragmentación de las muestras arqueomalacológicas y evaluar las condiciones de integridad de los depósitos arqueológicos conformados por exoesqueletos de moluscos.

\section{Agradecimientos}

Al Dr. Leandro Zilio por la realización de las figuras. A los evaluadores y a los editores de la revista. Este trabajo se realizó en el marco del proyecto "Estudios regionales en el eje Deseado (cuencas media e inferior) para definir los rangos de acción de grupos cazadores recolectores costeros en el marco de la ocupación humana del Holoceno de Patagonia" (11/N 739, UNLP) dirigido por la Dra. A. Castro. A la Universidad Nacional de la Plata y al Consejo Nacional de Investigaciones Científicas y Técnicas (Becas Postdoctorales de las autoras).

\section{Bibliografía}

AGUIRRE, M. L. y FARINATI, E. A. (2000): "Moluscos del Cuaternario marino de la Argentina". Boletín de la Academia Nacional de Ciencias, 64:235-333.

ÁlVAREZ, M.; GODINO, I. B.; BALBO, A. y MADELLA, M. (2011): "Shell middens as archives of past environments, human dispersal and specialized resource management". Quaternary International, 239(1):1-7.

ANGELBECK, G. (2011): "Stone tools and shellfish. Ancient shellfish harvesting on the former Transkei coast". The Digging Stick, 28(2):11-13.

ARRIGONI, I. G. y PALEO, M. C. (1992): "Investigaciones en la región central del Golfo San Jorge". Sinchal, 206-210.

BADAL GARCÍA, E. (1992): “L'anthracologiepréhistorique: à propos de certains problèmes méthodologiques. Les Charbons de Bois les Anciens Écosystèmes et le rôle de L'Homme". Bulletin de la Société Botanique de France, 139:167-189.

BONIZZONI, L.; BRUNI, S.; GIROD, A.; y GUGLIELMI, V. (2009): “Archaeometric study of shells of Helicidae from the Edera Cave (Northeastern Italy)". Archaeometry, 51(1):151173. 
CABRAL, J. P.; y DA SILVA, A. C. (2003): "Morphometric analysis of limpets from an Iron-Age shell midden found in northwest Portugal". Journal of Archaeological Science, 30(7):817-829.

CARDOSO, M. B.; LADIO, A. H.; DUTRUS, S. M.; y LOZADA, M. (2015): "Preference and calorific value of fuelwood species in rural populations in northwestern Patagonia". Biomass and Bioenergy, 81:514-520.

CASTRO, A.; MORENO, J.; ANDOLFO, M.; GIMÉNEZ, R.; PEÑA, C.; MAZZITELLI, L.; ZUBIMENDI, M. y AMBRÚSTOLO, P. (2003): “Análisis distribucionales en la costa de Santa Cruz (Patagonia Argentina): alcances y resultados”. Magallania, 31:69-94.

CHABAL, L. (1988): "Pourquoi et comment prélever les charbons de bois pour la période antique, les méthodes utilisé es sur le site de Lattes (Hérault)". Lattara, 1:187-222.

CHABAL, L. (1990): "L'étude paléoécologique des sites protohistoriques à partir des charbons de bois, la question de l'unité de mesure. Dénombrement de fragments ou pesées?" En: HACKENS, T.; MUNAUT, A. V. y TILL, C. (eds.): Wood and Archaeology, first conference, pp. 189-205, PACT 22, Louvain la-Neuve.

CIAMPAGNA, M. L. (2016): "Prácticas en la gestión de recursos vegetales silvestres de grupos cazadores recolectores en los sitios Cormorán Quemado y Nido del Águila, Costa Norte de Santa Cruz, Patagonia, Argentina”. En MENA, F. (ed.): Arqueología de Patagonia, de mar a mar, pp. 345-354, Andros Impresores, Santiago de Chile.

CIAMPAGNA, M. L. (2015): Estudio de la interacción entre grupos cazadores recolectores de Patagonia y las plantas silvestres: el caso de la costa norte de Santa Cruz durante el Holoceno medio y tardío. Tesis doctoral inédita, Universidad Nacional de La Plata, Argentina.

CLAASSEN, C. (1998): Shells. Cambridge manuals in archaeology. Cambridge University Press, New York.

COHEN, A. L. y BRANCH, G. M. (1992): "Environmentally controlled variation in the structure and mineralogy of Patella granularis shells from the coast of southern Africa: implications for palaeotemperature assessments". Palaeogeography, Palaeoclimatology, Palaeoecology, 91(1):49-57.

FAVIER DUBOIS, C. y BORELLA, F. (2007): “Consideraciones acerca de los procesos de formación de concheros en la costa Norte del golfo San Matías (Río Negro, Argentina)". Cazadores-recolectores del Cono Sur, 2:151-165.

FAULKNER, P. (2011): "Quantifying shell weight loss in archaeological deposits". Archaeology in Oceania, 46(3):118-129.

FUCHIGAMI, T. y SASAKI, T. (2005): “The shell structure of the recent Patellogastropoda (Mollusca: Gastropoda)". Paleontological Research, 9(2):143-168.

GAFFEY, S. J.; KOLAK, J. J. y BRONNIMANN, C. E. (1991): "Effects of drying, heating, annealing, and roasting on carbonate skeletal material, with geochemical and diagenetic implications". Geochimica et Cosmochimica Acta, 55(6):1627-1640. 
GÓMEZ OTERO, J. (2006). Dieta, uso del espacio y evolución en poblaciones cazadoras recolectoras de la costa centro-septentrional de Patagonia durante el Holoceno medio y Tardío. Tesis doctoral inédita, Universidad de Buenos Aires, Argentina.

GUSINDE, M. 1986 [1937]. Los indios de Tierra del Fuego. Tomo II: Los Yámana. Centro Argentino de Etnología Americana, Buenos Aires.

GUTIÉRREZ ZUGASTI, I. (2008a): “Análisis tafonómico en arqueomalacología: el ejemplo de los concheros de la región cantábrica”. Krei, 10:53-74.

GUTIÉRREZ ZUGASTI, I. (2008b): La explotación de moluscos y otros recursos litorales en la región cantábrica durante el pleistoceno final y el Holoceno inicial. Tesis doctoral inédita, Universidad de Cantabria, España.

HAMMOND, H. (2015): Sitios concheros en la costa norte de Santa Cruz: su estructura arqueológica y variabilidad espacial en cazadores recolectores patagónicos. Tesis doctoral inédita, Universidad Nacional de La Plata, Argentina.

HAMMOND, H. (2014): "Taphonomic analysis of archaeomalacological assemblages: shell middens on the northern coast of Santa Cruz (Patagonia, Argentina)". Intersecciones en Antropología, Volumen especial, 1:21-34.

HAMMOND, H. (2013): "Propuesta metodológica para el estudio de conjuntos malacológicos de sitios concheros: su aplicación en la costa norte de Santa Cruz (Patagonia argentina)". La Zaranda de Ideas, 9 (2):77-102.

HAMMOND, H. y ZILIO, L. (2016a): “Cambios en el tamaño de exoesqueletos calcáreos de moluscos durante el Holoceno tardío: arqueomalacología de concheros en la costa norte de Santa Cruz, Patagonia argentina". Arqueología Iberoamericana, 32: 17-24.

HAMMOND, H. y ZILIO, L (2016b): “Experimentación del proceso de recolección de moluscos marinos en la costa patagónica: análisis de la especie Nacella magellanica y sus implicancias en la interpretación de muestras arqueomalacológicas". Comechingonia, 20(2): 265-290.

HAMMOND, H.; ZUBIMENDI, M. y ZILIO, L. (2013): “Composición de concheros y uso del espacio: aproximaciones al paisaje arqueológico costero en Punta Medanosa”. Anuario de Arqueología, 5:67-84.

JERARDINO, A. (1997): "Changes in shellfish species composition and mean shell size from a late-Holocene record of the west coast of southern Africa". Journal of Archaeological Science, 24(11):1031-1044.

MARITAN, L.; MAZZOLI, C. y FREESTONE, I. (2007): "Modelling changes in mollusc shell internal microstructure during firing: implications for temperature estimation in shellbearing pottery". Archaeometry, 49(3):529-541.

MUÑOZ, A. S.; CARACOTCHE, M. S. y CRUZ, I. (2009): “Cronología de la costa al sur del río Santa Cruz: nuevas dataciones radiocarbónicas en Punta Entrada y Parque Nacional Monte León (Provincia de Santa Cruz, Argentina)”. Magallania, 37(1):193-197. 
ORQUERA, L. A. (1999): El consumo de moluscos por los canoeros del extremo sur. Relaciones de la Sociedad Argentina de Antropología, 24:307-327.

ORQUERA, L. A. y PIANA, E. L. (2001): “Composición de conchales de la costa del Canal Beagle (Tierra del Fuego, República Argentina) -Segunda Parte-". Relaciones de la Sociedad Argentina de Antropología, 26:345-368.

ORQUERA, L. A. y PIANA, E. L. (2000): “Composición de conchales de la costa del Canal Beagle (Tierra del Fuego, República Argentina) -Primera Parte-". Relaciones de la Sociedad Argentina de Antropología, 25:249-274.

ORQUERA, L. y PIANA, E. (1999a): Arqueología de la región del Canal Beagle: Tierra del Fuego, República Argentina, Sociedad Argentina de Antropología, Buenos Aires.

ORQUERA, L. y PIANA, E. (1999b): La vida social y material de los Yámana, Editorial Eudeba, Buenos Aires.

ORQUERA, L. A. y PIANA, E. (1992): "Un paso hacia la resolución del palimpsesto". En BORRERO, L. A. y LANATA (eds.): Análisis espacial en la arqueología patagónica, pp. 21-52, Ediciones Ayllu, Buenos Aires.

ORTEGA, F. V. y MARCONETTO, M. B. (2009): "Una discusión encendida. Primeros resultados de los análisis de vestigios de combustión en concheros de la Costa Norpatagónica (Río Negro)". En SAlEMME, M.; SANTIAGO, F.; ÁlVAREZ, M.; PIANA, E.; VÁZQUEZ, M. y MANSUR, E. (eds.): Arqueología de Patagonia: una mirada desde el último confín, vol. 2, pp. 1141-1148, Utopías, Ushuaia.

ORTON, J, y HALKETT, D. (2006): Mitigation of archaeological sites within the Buffels Marine and Koingnaas Complexes, Namaqualand, Sept 2005 to May 2006. Report prepared for De Beers Consolidated Mines NM. Archaeology Contracts Office, UCT.

ORTON, J.; JERARDINO, A. y HALKETT, D. (2012): “On limpets, their height and how to get them on the plate". The Digging Stick, 29(1):13-14.

OTAEGUI, A.V. (1974): "Las especies del genero Patinigera Dall, 1905 en la Provincia Magallánica (Mollusca, Gastropoda, Prosobranchiata)”. Physis, 33:173-184.

PAILLER, Y.; DUPONT, C.; SPARFEL, Y. y LEROY, A. (2007): “Analyse fonstionnelle des galets biseautés du Médolithique à la fin du Néolithique dans I‘Oquest de la France, la Grande-Bretagneet I Irlande”. Bulletin de la Société préhistorique francaise, 104(1):31-54.

PIQUÉ I HUERTA, R. (1999): Producción y uso del combustible vegetal: una evaluación arqueológica. Treballs d'Etnoarqueología, 3, Universidad Autónoma de Barcelona, CSIC, Bellaterra.

SANTIAGO, F.; GORDILlO, S. y SALEMME, M. (2015): "Moluscos en contextos arqueológicos de la costa atlántica de Tierra del Fuego: consumo prehistórico e implicancias de su distribución actual". Revista Chilena de Antropología, (29):40-48.

SUZUKI, M.; KAMEDA, J.; SASAKI, T.; SARUWATARI, K.; NAGASAWA, H., y KOGURE, T. (2010): "Characterization of the multilayered shell of a limpet, Lottia 
kogamogai (Mollusca: Patellogastropoda), using SEM-EBSD and FIB-TEM techniques”. Journal of structural biology, 171(2):223-230.

VERDÚN, E. (2014): "El consumo de moluscos en sociedades cazadoras-recolectoras de Tierra del Fuego (Argentina)". En ORÍA, J. y A. TÍVOLI (eds.): Cazadores de mar y tierra. Estudios recientes en arqueología fueguina, pp. 363-387, Editora cultural Tierra del Fuego, Museo del Fin del Mundo, Ushuaia.

VILLAGRÁN, X. S. (2014): "Experimental Micromorphology on Burnt Shells of Anomalocardia brasiliana (Gmelin 1791) (Bivalvia, Veneridae) and Its Potential for Identification of Combustion Features on Shell-Matrix Sites". Geoarchaeology, 29(5): 389396.

VILLAGRÁN, X. S.; BALBO, A. L.; MADELLA, M.; VILA, A. y ESTEVEZ, J. (2011): "Experimental micromorphology in Tierra del Fuego (Argentina): building a reference collection for the study of shell middens in cold climates". Journal of Archaeological Science, 38(3):588-604.

VILLAMARZO, E. (2009): "Estudio experimental sobre valvas de Berberechos (Donax hanleyanus)". En BEOVIDE, L.; ERCHINI, C. y FIGUEIRO, G. (eds.): La arqueología como profesión: los primeros 30 años. XI Congreso Nacional de Arqueología Uruguaya, pp. 745-754, Asociación Uruguaya de Arqueología, Montevideo.

ZANGRANDO, A. F.; BORRAZZO, K.; TIVOLI, A.; ALUNNI, D. y MARTINOLI, M. P. (2014): "El Sitio Heshkaia 35: nuevos datos sobre la arqueología de Moat (Tierra del Fuego, Argentina)". Revista del Museo de Antropología, 7(1):11-24.

ZUBIMENDI, M. (2012): “La variabilidad del registro arqueomalacológico en la costa norte de Santa Cruz (Patagonia argentina): resultados exploratorios a partir de estudios estratigráficos". Intersecciones en Antropología, 13(2):359-375.

ZUBIMENDI, M.; HAMMOND, H. y L. ZILIO. (2015): “Síntesis regional de las malacofaunas presentes en sitios arqueológicos de la Patagonia continental Argentina". En HAMMOND, H. y ZUBIMENDI, M. A. (eds.): Arqueomalacología: abordajes metodológicos y casos de estudio en el Cono Sur, pp. 175-245, Vázquez Mazzini Editores, Buenos Aires. 